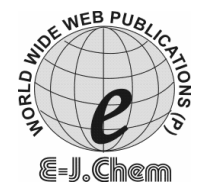

http://www.e-journals.net
ISSN: 0973-4945; CODEN ECJHAO

E-Journal of Chemistry 2009, 6(1), 141-150

\title{
Preparation of Silica Modified with 2-Mercaptoimidazole and its Sorption Properties of Chromium(III)
}

\author{
HARRY BUDIMAN*, FRANSISKA SRI H.K and ACHMAD. H. SETIAWAN
}

\author{
Research Centre for Chemistry, Indonesian Institute of Sciences, \\ Kawasan PUSPIPTEK, Serpong, Banten 15314, Indonesia. \\ atomic_chem@yahoo.com
}

Received 28 February 2008; Revised 21 July 2008; Accepted 10 September 2008

\begin{abstract}
Modified silica gel was prepared to remove the heavy metal of chromium(III) from water sample. Silica gel was used as supporting material and the 2-mercaptoimidazole was immobilized onto surface silica so that the silica would have selective properties to adsorb the heavy metal chromium(III) through the formation of coordination compound between the 2-mercaptoimidazole and chromium(III). The characterization of modified silica gel was carried out by analyzing the Fourier Transform Infrared Spectrum of this material in order to ensure the immobilization of 2-mercaptoimidazole onto the surface. The effect of $\mathrm{pH}$ solution, initial concentration of chromium(III), and interaction time were investigated in batch mode to find the adsorption properties of chromium(III) onto modified silica. The condition optimum of these parameters was applied to determine the removal percentage of chromium(III) in water sample using the modified silica gel.
\end{abstract}

Keywords: Heavy metal, Chromium(III), Adsorption, Silica, 2-Mercaptomidazole

\section{Introduction}

Nowadays, the heavy metal pollution has become big problem in the world since the heavy metal in particular concentration can affect to the human and organism body. Heavy metal in trace concentration is extremely needed by life process for instance the human body need some minerals to support the metabolism process. However, heavy metal in high concentration can cause illness or poisonous for human such as dysfunction of nerve system, blood composition changing, heart and lungs disease, etc. For example, the excessive exposure and inhalation of chromium can cause various diseases and damage the liver, kidney, circulatory system, nerve tissue, and blood forming organs ${ }^{1}$. Therefore, analytical method and separation technology has been developed to identify the heavy metal pollution in recent days. 
Several techniques can be used for separation and preconcentration of trace heavy metal such as liquid-liquid extraction, solid phase extraction, coprecipitation, ion exchange, floatation, and electrochemistry deposition ${ }^{2,3}$. Solid phase extraction is the most frequently technique used for separation and preconcentration of heavy metal because it unnecessary to use the dangerous solvent. In this technique, many materials are used as adsorbent such as polymer resin, porous glass silica, and silica modified by grafting or sol gel method ${ }^{4}$. For analytical purposes, silica modified by organic functional group is commonly used since the material silica provides many advantages such as inert, good adsorption and cation exchange capacity, easy to prepare with chemical compound and particular impregnate medium to create several of modified silica surface, high mechanic and thermal stability. In addition, the retention processes of analyte (adsorption, ion exchange, chelate complex formation) on silica surface is reversible so that the silica adsorbent could be used for preconcentration and separation ${ }^{5,6}$.

The modification of silica by organic functional group could enhance the adsorption and ion exchange capability of silica gel so that it has good selectivity for metal ions. Chemical compounds contained donor atom such as sulfur, nitrogen, phosphor, oxygen are commonly used to modify silica surface. There are two processes to immobilization the organic functional group onto silica surface such as chemical adsorption and physical adsorption. In chemical adsorption, the donor atom of organic compound chemically bonded with amine or chloro group attached on silica surface. Meanwhile, in physical adsorption, the organic functional groups physically adsorbed onto silica surface ${ }^{5}$.

Since modified silica has high surface area and high mechanical stability, it usually uses for catalysis application. In the other hand, modified silica gel also can be used for precocentration and separation of trace metal before on line precocentration analysis with flow injection flame Atomic Absorption Spectrometry (AAS), spectrophotometry, potentiometry and electrochemistry, Inductively Coupled Plasma Atomic Emission Spectrometry (ICP-AES) ${ }^{2,7-9}$. The use of modified silica with organic functional group has become the interesting research object at the moment ${ }^{5}$. Some organic compound has been used to modify silica gel for heavy metal removal purposes such as 5-formyl(1-carboxyphenyazo)salicylic acid, 8-hydroxyquinoline, tetra(2aminoethyl)-ethylenediamine, 3-methyl-1-phenyl-5-pyrazone, 1,8-dihydroxyanthraquinone, dihydroxybenzen, 1,10-phenanthroline, 1-(2-thiazolyazo)-2-napthol, 1,5-bis(di-2-pyridil) methylenethiocarbohydrazide, 2-[2-(6-methyl-benzothiazolyazo]-4-bromophenol ${ }^{10,11}$.

This article describes modified silica with 2-mercaptoimidazole. Activated silica gel was modified first with 3-chloropropyltrimethoxysilane to load the chlor group which will bond with the organic functional group contained in 2-mercaptoimidazole. Then the sorption behavior of chromium(III) in modified silica has been investigated. The modified silica with 2-mercaptoimidazole was applied to remove the chromium(III) from the water sample.

\section{Experimental}

\section{Chemicals and reagents}

The chemicals are pro analysis grade consist of Silica gel, 3-chloropropyltrimethoxysilane, 2-mercaptoimidazole, chrom(III) nitrate nonahydrate, sodium hydrogenphosphat, citric acid, ethanol, toluene, sodium sulfate anhydrous, demineralized water, nitrogen gas flow, hydrochloric acid.

\section{Instruments}

Reflux apparatus for preparing the silica modified. Shaker Micromat for shaking the silica modified in chromium(III) solution. Vacuum oven for drying the silica modified. Fourier 
Transform Infrared Spectrometer (FT-IR) Shimadzu for characterization of silica modified. Meanwhile, Graphite Furnace Atomic Absorption Spectrometer SpectrAA-880 Zeeman Varian measured chromium(III) remained in solution.

\section{Preparation of silica modified with 2-mercaptoimidazole}

\section{Silica activated}

$10 \mathrm{~g}$ of silica gel was immersed in $50 \mathrm{~mL}$ hydrochloric acid of $4 \mathrm{M}$. This mixture was allowed to reflux with stirring for $4 \mathrm{~h}$. Then, it was filtered and washed with demineralized water until acid free. The silica was dried in furnace $150^{\circ} \mathrm{C}$ for $5 \mathrm{~h}$. Silica activated was characterized by Fourier Transform Infrared Spectrometry.

Silica loaded with 3-chloropropyltrimethoxysilane (Si-CTS)

$1 \mathrm{~g}$ of activated silica was mixed with $20 \mathrm{~mL}$ dry toluene and $2.5 \mathrm{~mL}$ 3-chloropropyl trimethoxysilane. The mixture was refluxed at $70-80^{\circ} \mathrm{C}$ with stirring for $8 \mathrm{~h}$. Then, it was filtered and washed with dry toluene, and dry acetone. The Si-CTS was dried in vacuum oven at $70^{\circ} \mathrm{C}$ for $3 \mathrm{~h}$. Si-CTS was characterized by Fourier Transform Infrared Spectrometry.

\section{Si-CTS modified 2-mercaptoimidazole (Si-CTS-MCP)}

$40 \mathrm{~mL}$ of dry toluene and $5 \mathrm{~mL}$ of $4 \%$ (v/v) 2-mercaptoimidazole solution was added into $1 \mathrm{~g}$ of Si-CTS. The mixture was allowed to reflux at $70-80^{\circ} \mathrm{C}$ under nitrogen flow condition for $8 \mathrm{~h}$. Modified silica was filtered and washed with toluene to remove 2-mercaptoimidazole unattached into silica. Finally, it was dried in oven vacuum at $50^{\circ} \mathrm{C}$ for $3 \mathrm{~h}$. Si-CTS-MCP was characterized by Fourier Transform Infrared Spectrometry.

\section{Sorption behavior of chromium(III) on silica modified}

Stock solution of chromium(III) $1000 \mathrm{mg} / \mathrm{L}$

$0.777 \mathrm{~g}$ of chrom(III) nitrate nonahydrate was dissolved in $100 \mathrm{~mL}$ of demineralized water.

\section{Effect of $p H$}

Solution of chromium(III) with concentration of $5 \mathrm{mg} / \mathrm{L}$ was prepared from dilution of stock solution of chromium(III) in $1000 \mathrm{mg} / \mathrm{L} .50 \mathrm{mg}$ of investigated adsorbent (Si-CTSMCP) was suspended with constant shaking for one hour in $10 \mathrm{~mL}$ of $5 \mathrm{mg} / \mathrm{L}$ chromium(III) solution at desired $\mathrm{pH}$ with range (2-10). The solution was filtered, and then the filtrate was analyzed by atomic absorption spectrometry for the amount of chromium(III) being adsorbed.

\section{Effect of initial concentration}

After the $\mathrm{pH}$ optimum for adsorption of chromium in investigated silica was found, $50 \mathrm{mg}$ of Si-CTS-MCP was immersed and allowed to shake for one hour in $10 \mathrm{~mL}$ of various concentrations chromium(III) solution $(0.5-200 \mathrm{mg} / \mathrm{L})$ at $\mathrm{pH}$ optimum. The solution was filtered. Then, the concentration of chromium(III) contained in the filtrate was determined by atomic absorption spectrometry. The quantity of chromium(III) adsorbed by $1 \mathrm{~g}$ of adsorbent is commonly called the metal ion adsorption capacity "a". The "a" value can be calculated with formula as described below ${ }^{4}$.

$$
\alpha=\frac{\left(\mathrm{C}_{0}-\mathrm{C}_{1}\right)}{\mathrm{m}} \times \mathrm{V}
$$


Where, $a$ is the metal ion adsorption capacity ( $\mathrm{mg} / \mathrm{g}$ adsorbent), $\mathrm{C}_{o}$ is the initial concentration of metal ion $(\mathrm{mg} / \mathrm{L}), \mathrm{C}_{1}$ is the metal ion concentration at the equilibrium found in the solution $(\mathrm{mg} / \mathrm{L}), m$ is the mass of adsorbent $(\mathrm{g})$, and $\mathrm{V}$ is total volume of solution $(\mathrm{mL})$

\section{Effect of interaction time}

$50 \mathrm{mg}$ of Si-CTS-MCP was immersed in $10 \mathrm{~mL}$ of $5 \mathrm{mg} / \mathrm{L}$ chromium(III) solution (0.5-200 $\mathrm{mg} / \mathrm{L})$ at $\mathrm{pH}$ optimum and allowed to shake for different periods $(0-80 \mathrm{~min})$. The solution was filtered, and then the filtrate was analyzed by atomic absorption spectrometry for the amount of chromium(III) being adsorbed.

\section{Separation of Chromium(III) from water sample by modified silica}

$10 \mathrm{~mL}$ of water sample was added with $5 \mathrm{mg} / \mathrm{L}$ of chromium(III) solution. Then $50 \mathrm{mg}$ of Si-CTS-MCP was suspended with constant shaking in $10 \mathrm{~mL}$ of water sample at $\mathrm{pH}$ and shaking time optimum. The concentration of chromium(III) contained in the supernatant was determined by atomic absorption spectrometry to investigate the amount of chromium(III) adsorbed onto Si-CTS-MCP. The \% removal of chromium(III) by Si-CTS-MCP was calculated with the following formula:

$$
\% \text { Removal of chromium }(\mathrm{III})=\frac{[\text { Chromium }(\mathrm{III}) \text { adsorption }]}{[\text { Chromium(III) initial }]} \times 100 \%
$$

\section{Result and Discussion}

\section{Preparation of silica modified with 2-mercaptoimidazole}

\section{Characterization of activated silica}

The Fourier Transform Infrared (FT-IR) spectrum of activated silica shown in Figure 1. The silanol group was observed by the presence of $-\mathrm{OH}$ stretch at $3207.62 \mathrm{~cm}^{-1}, 3479.62 \mathrm{~cm}^{-1}$ bands, while the siloksan (Si-O-Si) groups was observed at $1107.14 \mathrm{~cm}^{-1}$ band. Both of those groups are responsible as active site of silica gel which can be modified.

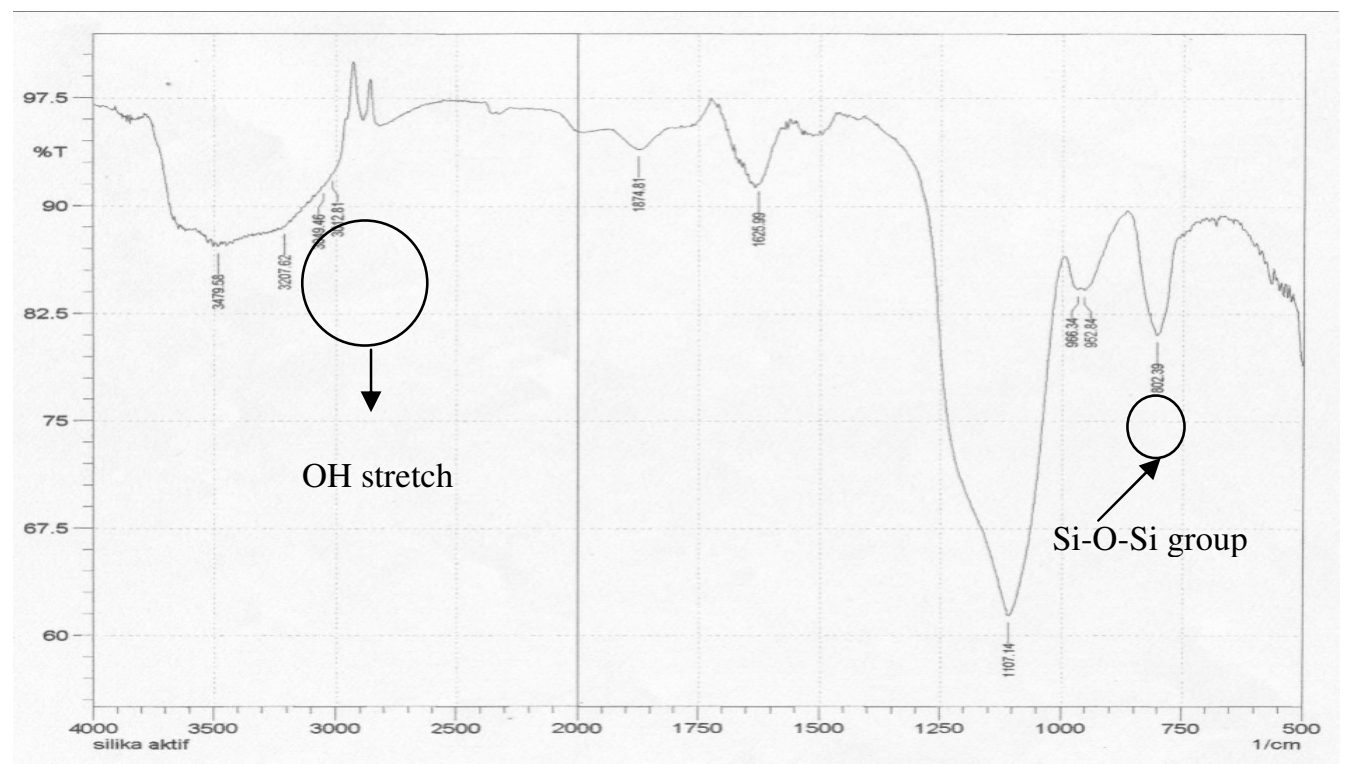

Figure 1. FT-IR spectrum of activated silica. 
The silica has to be activated first before modification process with organic functional group. In the activation of silica, silica was immersed in hydrochloric acid solution to remove the trace metal ${ }^{12}$ and dried in $150^{\circ} \mathrm{C}$ for $3 \mathrm{~h}$ to evaporate the water molecules which bonded in silanol group ( $\mathrm{Si}-\mathrm{OH})$ through hydrogen bonding so that the silanol groups can form covalent bond with the functional groups of compound ${ }^{13}$. In the other hand, the loss of water molecule from silica caused the bigger surface area and the pore of silica so that physical adsorption, chemical adsorption, and capillary condensation process become more efficient and effective. The scheme of activated silica was shown in Figure 2.

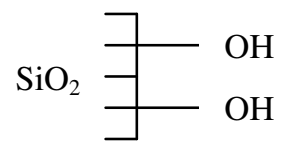

Figure 2. Scheme of activated silica ${ }^{5}$.

\section{Characterization of $\mathrm{Si}$-CTS}

Characterization of Si-CTS with FT-IR showed the presence of aliphatic C-H stretch at $2958.80 \mathrm{~cm}^{-1}$ band, $\mathrm{C}-\mathrm{H}$ bend at $1442.75 \mathrm{~cm}^{-1}$ and $1408.04 \mathrm{~cm}^{-1}$ bands which are corresponding to 3-chloropropyltrimethoxysilane, as shown in Figure 3.

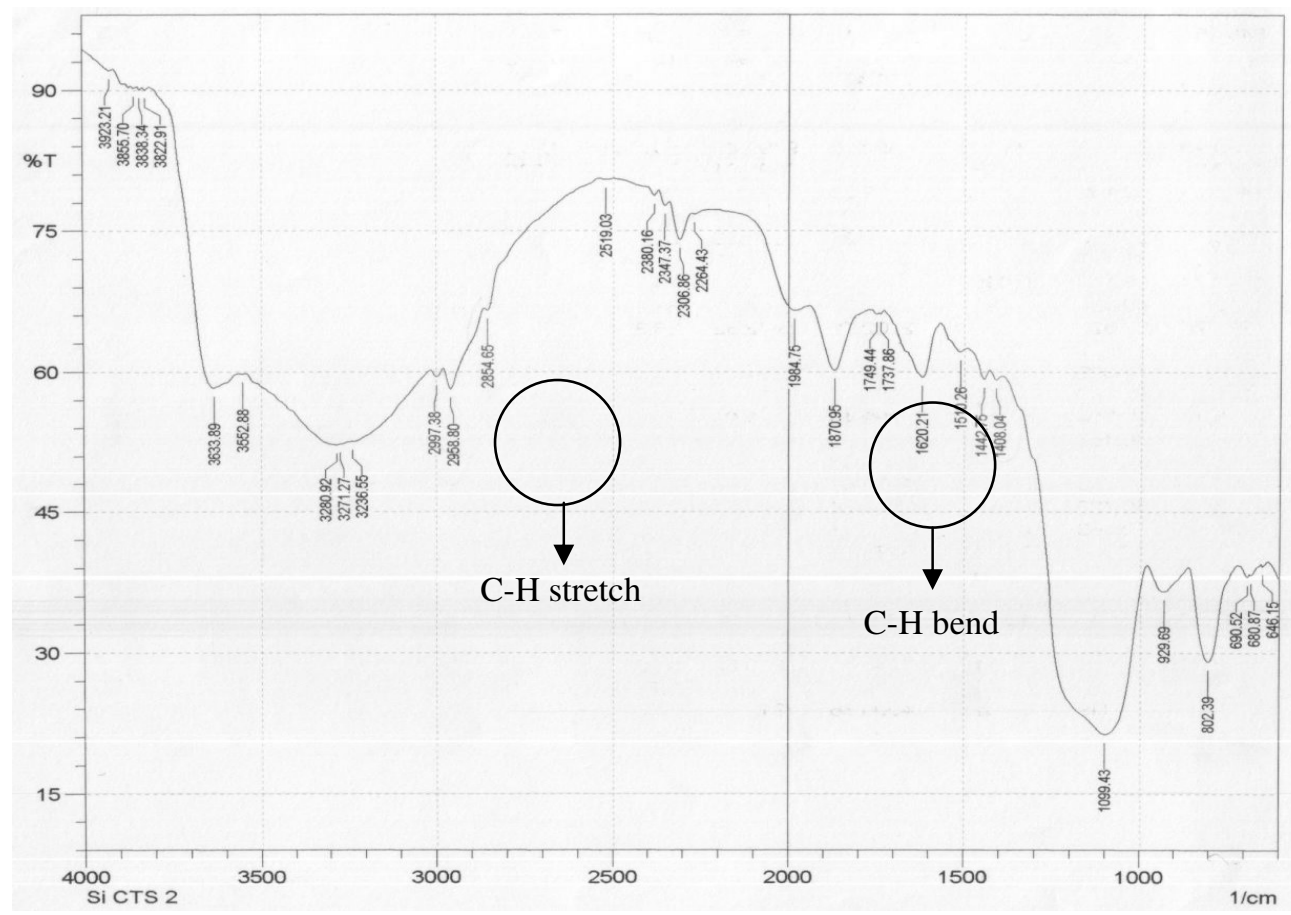

Figure 3. FT-IR spectrum of Si-CTS.

Silica activated was modified with 3-chloropropyltrimethoxysilane to attach chlor group into silica before immobilization with 2-mercaptoimidazole ${ }^{16,17}$. Furthermore, 3-chloro propyltrimethoxysilane was important needed as intermediate reagent to immobilize heterocyclic compound such as 2-mercaptoimidazole into silica surface ${ }^{14}$. The scheme of SiCTS was shown in Figure 4. 
<smiles></smiles>

Figure 4. Scheme of $\mathrm{Si}_{-} \mathrm{CTS}^{5}$.

\section{Characterization of Si-CTS-MCP}

Modification of Si-CTS with 2-mercaptoimidazole ligand showed that the ligand was successfully immobilized to silica. The S-H stretch at $2630 \mathrm{~cm}^{-1}, \mathrm{~N}-\mathrm{H}$ bend at $1585 \mathrm{~cm}^{-1}$, $\mathrm{C}-\mathrm{S}$ stretch at $673.16 \mathrm{~cm}^{-1}$, and $\mathrm{C}=\mathrm{C}$ stretch at $3128.54 \mathrm{~cm}^{-1}$ can be observed from the IR spectrum of Si-CTS-MCP ${ }^{15}$, as shown in Figure 5.

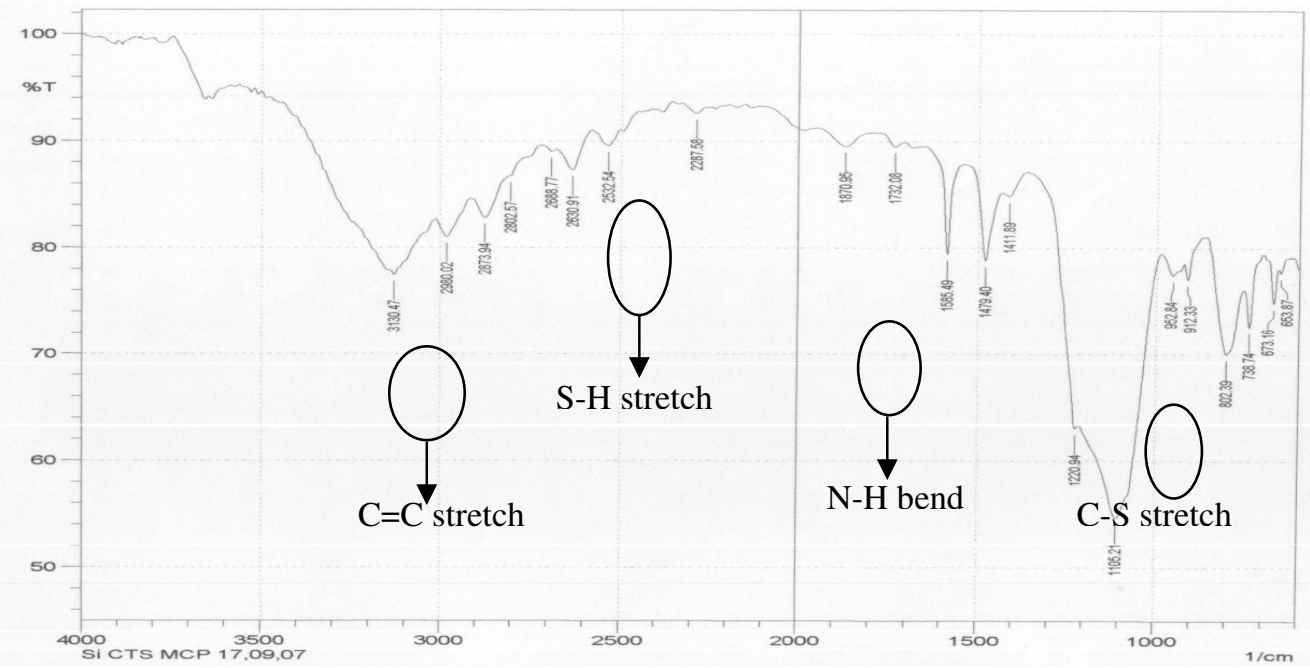

Figure 5. FT-IR spectrum of Si-CTS-MCP.

2-Mercaptoimidazole ligand can be immobilized to the silica because the nucleophilic substitution reaction mechanism $\left(\mathrm{SN}_{2}\right)$ occurred between the chlor group from3chloropropyltrimethoxysilane and 2-mercaptoimidazole ${ }^{14}$. The scheme of Si-CTS-MCP was described in Figure 6.<smiles>CO[Si](CCCSc1ncc[nH]1)(OC)OC</smiles>

Figure 6. Scheme of Si-CTS-MCP ${ }^{5}$.

\section{Sorption behavior of Chromium(III) on Si-CTS-MCP}

Effect of $p H$

Metal adsorption on silica modified with organic ligand occurred through the formation of coordination compound between metal ion and donor atom in organic ligand. Therefore, $\mathrm{pH}$ of solution is one of the most important parameter which effect to the concentration of metal adsorbed on the silica modified ${ }^{17}$. The $\%$ of chromium(III) adsorbed on Si-CTS-MCP and activated silica in various condition of $\mathrm{pH}(2-10)$ was described in Figure 7. 


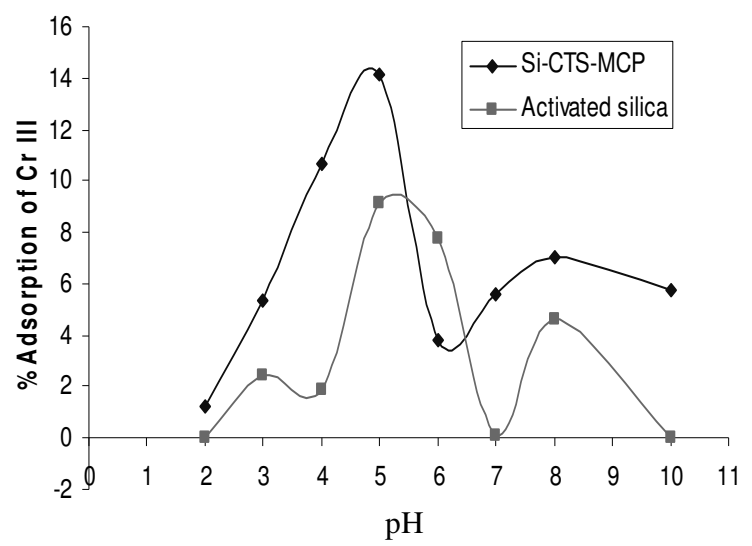

Figure 7. Effect of $\mathrm{pH}$ solution on percentage of chromium(III) adsorbed onto Si-CTS-MCP and activated silica.

Figure 7 showed that adsorption of chromium(III) gained optimum condition at $\mathrm{pH} 5$. Si-CTS-MCP can adsorb $14,151 \%$ of chromium(III) while $9,106 \%$ of chromium(III) can only be adsorbed by activated silica at particular $\mathrm{pH}$. Moreover, the percentage adsorption of chromium(III) was increased from the $\mathrm{pH}$ value 2-5. This indicated that the increasing of $\mathrm{pH}$ caused deprotonation of nitrogen atom in 2-mercaptoimidazole so that chromium(III) might form the coordination compound through two atom donors which is nitrogen and sulphur ${ }^{18}$, as described in Figure 8.

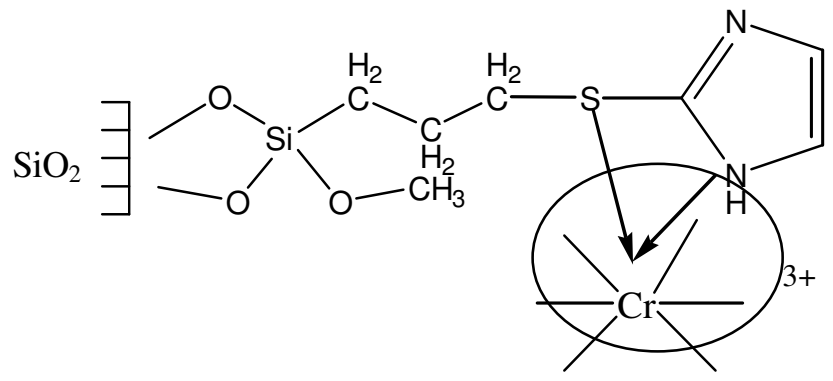

Figure 8. Scheme of the formation of coordination compound between chromium(III) and Si-CTS-MCP

Sulphur atom only roled as donor atom in forming covalent coordination bond at lower $\mathrm{pH}(\mathrm{pH} \mathrm{2})^{18}$. Meanwhile at higher $\mathrm{pH}(\mathrm{pH}$ 5) there is two atom donors such as nitrogen and sulphur in the formation of covalent coordination bond with ion metal so that more ions of chromium(III) attached onto silica modified with MCP than at lower $\mathrm{pH}$. The adsorption of chromium(III) onto Si-CTS-MCP decreased at $\mathrm{pH}$ higher than 5, as shown in Figure 5, because the presence of more ion $\mathrm{OH}^{-}$at $\mathrm{pH}$ closely to 14 responsible for the formation of chromium(III) coordination compound as hydroxyl complexes $\mathrm{Cr}(\mathrm{OH})_{3}$ which was remained in solution ${ }^{17}$.

\section{Effect of initial concentration chromium(III)}

The interaction of various concentration of chromium(III) $(5-250 \mathrm{mg} / \mathrm{L})$ onto adsorbent $\mathrm{Si}$-CTS-MCP and activated silica was carried out in $\mathrm{pH}$ optimum 5 for $1 \mathrm{~h}$ to determine the metal ion adsorption capacity, as shown in Figure 9. 


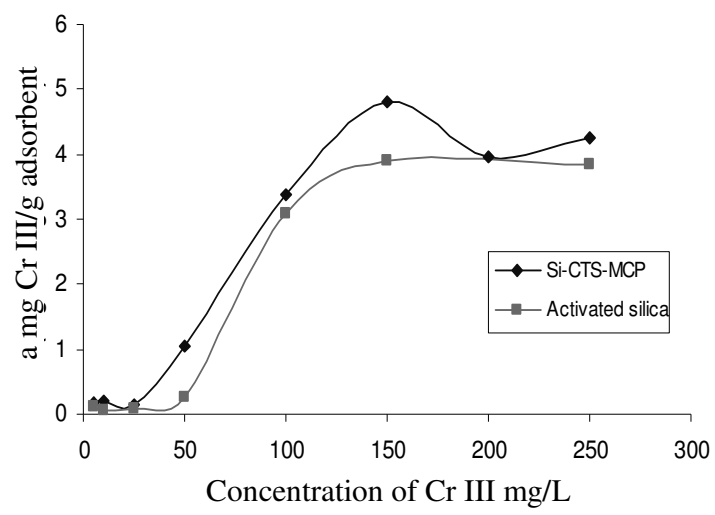

Figure 9. Effect of the initial concentration of chromium(III) on adsorption of chromium(III) onto $1 \mathrm{~g}$ of Si-CTS-MCP and activated silica.

Figure 9 described that the amount of chromium(III) adsorbed onto Si-CTS-MCP increased along with the increasing of the concentration of chromium(III) from $5 \mathrm{mg} / \mathrm{L}$ until $150 \mathrm{mg} / \mathrm{L}$. The increasing of concentration of chromium(III) caused more ion chromium(III) in solution which interacted and attached to the active site of the Si-CTS-MCP through the formation of covalent coordination bond between the ion chromium(III) and mercaptoimidazole. However, the number of active site in Si-CTS-MCP is constant at the fixed amount of adsorbent ${ }^{17}$, so the amount of chromium(III) would be constantly adsorbed onto Si-CTS-MCP in particular concentration of chromium(III). It is shown in Figure 9, the adsorption capacity of chromium(III) tend to constant at the initial concentration of chromium(III) higher than $150 \mathrm{mg} / \mathrm{L}$ which was indicated with the plateu graphic. It means that the whole active site in Si-CTS-MCP was fully attached by chromium(III).

\section{Effect of the interaction time (shaking time)}

In addition to $\mathrm{pH}$, the other factor effecting to the adsorption of chromium(III) onto Si-CTS_MCP is the interaction time of chromium(III) to reach the equilibrium with the Si-CTS-MCP. Figure 10 showed the amount of chromium(III) adsorbed onto Si-CTS-MCP in the various condition of interaction time where the experimental set in optimum $\mathrm{pH} 5$, and $5 \mathrm{mg} / \mathrm{L}$ of chromium(III) as initial concentration. The percentage adsorption of chromium(III) onto Si-CTS-MCP increased from $0 \%$ at $0 \mathrm{~min}$ until $16,068 \%$ at $80 \mathrm{~min}$.

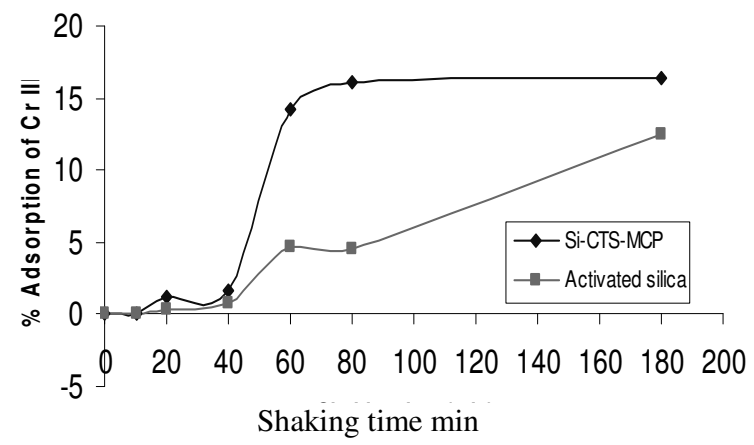

Figure 10. Effect of the interaction time on the percentage adsorption of chromium(III) onto Si-CTS-MCP and activated silica. 
However, from Figure 10, the amount of chromium(III) adsorbed by Si-CTS-MCP tend to constant at the interaction time higher than $80 \mathrm{~min}$ which was shown the plateu graph starting at $80 \mathrm{~min}$ till $180 \mathrm{~min}$. This indicated that the whole active sites of Si-CTS-MCP reached the equilibrium with the chromium(III) in solution so that Si-CTS-MCP cannot adsorb more ions chromium(III) in solution though the interaction time between chromium(III) and adsorbent was set longer than $80 \mathrm{~min}$.

\section{Separation of Chromium(III) from water sample by modified silica}

After the condition optimum of adsorption of chromium(III) onto Si-CTS-MCP had been determined, the Si-CTS-MCP was applied to remove the chromium(III) from the water sample. The water sample contained $5 \mathrm{mg} / \mathrm{L}$ of chromium(III) was interacted with the SiCTS-MCP at pH solution 5 for $80 \mathrm{~min}$. Table 1 showed that Si-CTS-MCP was able to remove $16.067 \%$ of chromium(III) from water sample.

Table 1. Percentage removal of Chromium(III) in water sample.

\begin{tabular}{|c|c|c|c|c|c|}
\hline \multirow[b]{2}{*}{ Replicates } & \multicolumn{2}{|c|}{ [Chromium(III)], mg/L } & \multirow{2}{*}{$\begin{array}{l}\% \text { Removal of } \\
\text { chromium(III) }\end{array}$} & \multirow{2}{*}{$\begin{array}{c}\text { Mean } \\
\% \text { removal of } \\
\text { chromium(III) }\end{array}$} & \multirow[b]{2}{*}{$\sigma$} \\
\hline & Initial & Adsorption & & & \\
\hline 1 & 5.280 & 0.805 & 15.246 & \multirow{2}{*}{16.067} & 1.160 \\
\hline 2 & 5.300 & 0.895 & 16.887 & & \\
\hline
\end{tabular}

\section{Conclusion}

The organic ligand 2-mercaptoimidazole was successfully immobilized onto silica through the reaction with 3-chloropropyltrimethoxysilane as intermediate reagent. This modified silica (Si-CTS-MCP) can optimally adsorb chromium(III) in $\mathrm{pH}$ solution 5 and interaction time $80 \mathrm{~min}$. It also can be interacted with the concentration of chromium(III) until 150 $\mathrm{mg} / \mathrm{L}$. When the modified silica was applied to remove chromium(III) from water sample, $16.067 \%$ of chromium(III) could be adsorbed by Si-CTS-MCP in optimum condition.

\section{Acknowledgement}

The authors would like to thanks to Eli Susilowati, Muhammad Ghozali for their support, and Indonesian Institute of Sciences (LIPI) 2007 Project for Research Centre for Chemistry who funded this research.

\section{References}

1. Sarkar B, Heavy Metals in the Environment, Marcel Dekker Inc, New York, 2002.

2. Liang P and Chen X, Anal Sci., 2005, 21, 1185-1188.

3. Shemirani F, Abkenar S D, Mirroshandel A A, Niasari M S and Kozania R R, Anal Sci., 2003, 19, 1453-1456.

4. De Moraes S V M, Tisott M M, Milcharek C D, Brasil J L, Costa T M H, Gallas M R, Benvenutti E V and Lima E C, Anal Sci., 2005, 21, 573-577.

5. Osman M M, Kholeif S A, Abou-Almaaty N A and Mahmoud M E, Anal Sci., 2004, 20, 847-852.

6. Pyrzynska K and Wierzbicki T, Anal Sci., 2005, 21, 951-954.

7. Lapanantnoppakhun, Somchai, Kasuwas S, Ganranoo L, Jakmunee J and Grudpan K, Anal Sci., 2006, 22, 153-155.

8. Matsuoka S, Shiota N and Yoshimura K, Anal Sci., 2006, 22, 177-181.

9. Sumida T, Sabarudin A, Oshima M and Motomizu S, Anal Sci., 2006, 22, 161-164. 
10. Abd-ElAziz Akl M A, Kenawy I M and Lasheen R R, Anal Sci., 2005, 21, 923-931.

11. Yebra Biurrun M C and Crespon Romero R M, Anal Sci., 2006, 22, 51-55.

12. Peng Liu, J Anal At Spectrom., 2002, 17, 125-130.

13. Misra B K, Jal P K, Patel S, Talanta., 2004, 62, 1005-1028.

14. Foschiera J L, Pizzolato T M and Benvennuti E V, J Braz Chem Soc., 2001, 12(2), 159-164.

15. John Coates, Interpretation of Infrared Spectra, A Practical Approach, R A Meyers (Ed.), Encyclopedia of Analytical Chemistry, John Willey \& Sons Ltd, Cinchester, 2000, pp.10815-10837.

16. Fujiwara S T and Gushikem Y, J Braz Chem Soc., 1999, 10(5), 389-393.

17. Oo C W, \& Jain, K, Indo J Chem., 2007, 7(2), 180-184.

18. Dias Filho N L, do Carmo D R, Caetano L and Rosa A H, Anal Sci., 2005, 21, 1359-1363. 


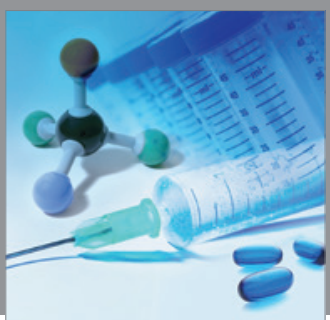

International Journal of

Medicinal Chemistry

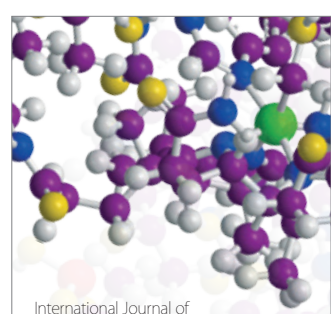

Carbohydrate Chemistry

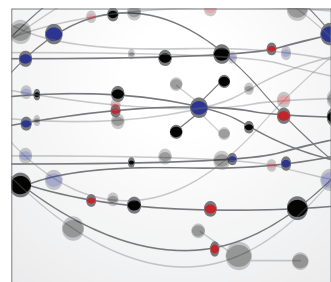

The Scientific World Journal
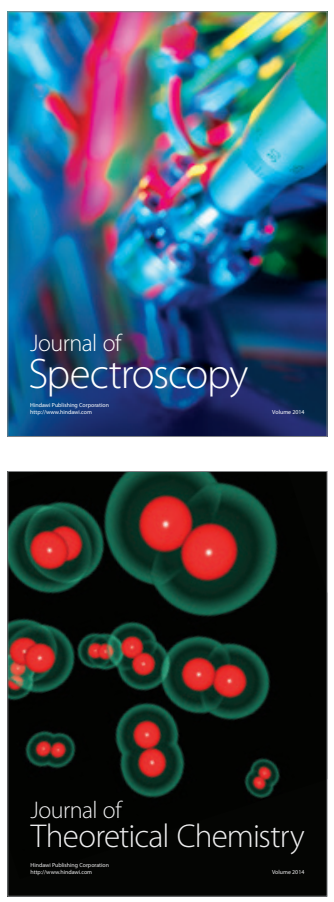
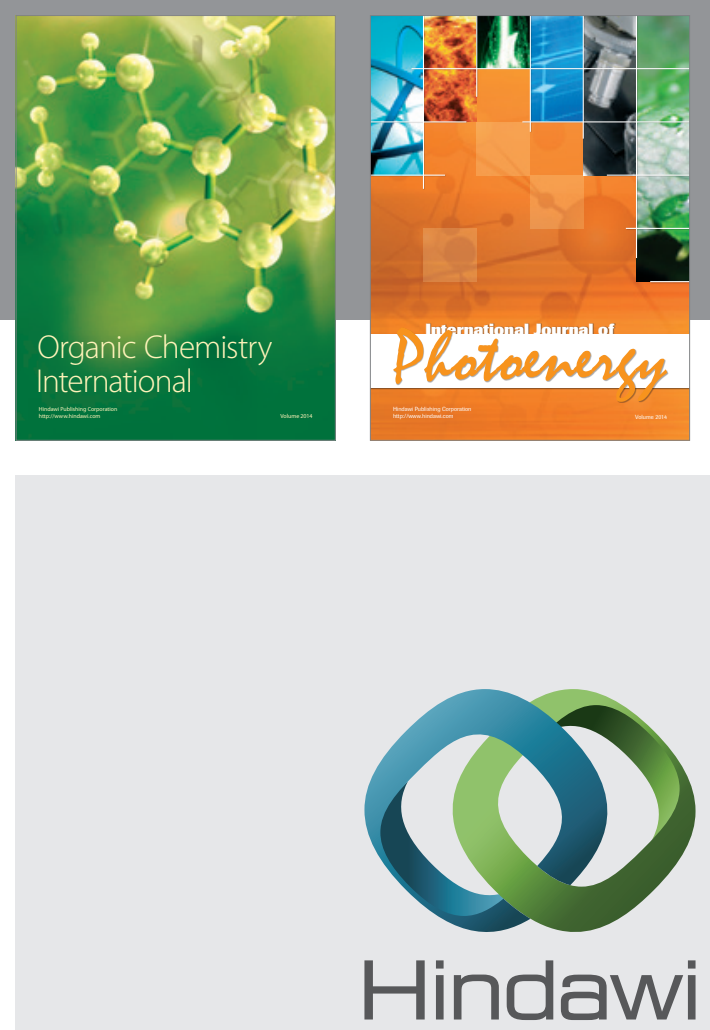

Submit your manuscripts at

http://www.hindawi.com
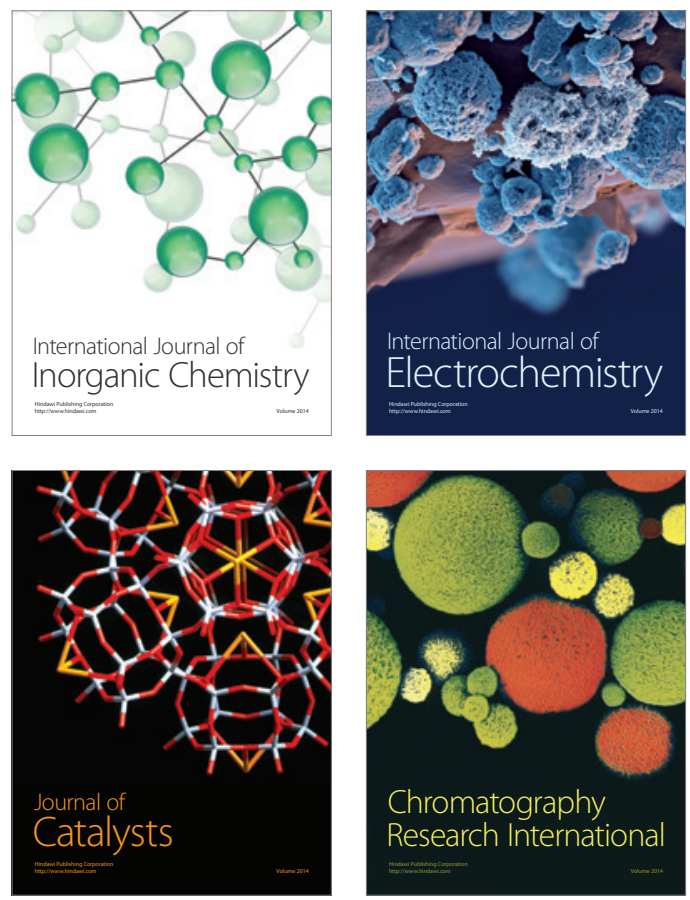
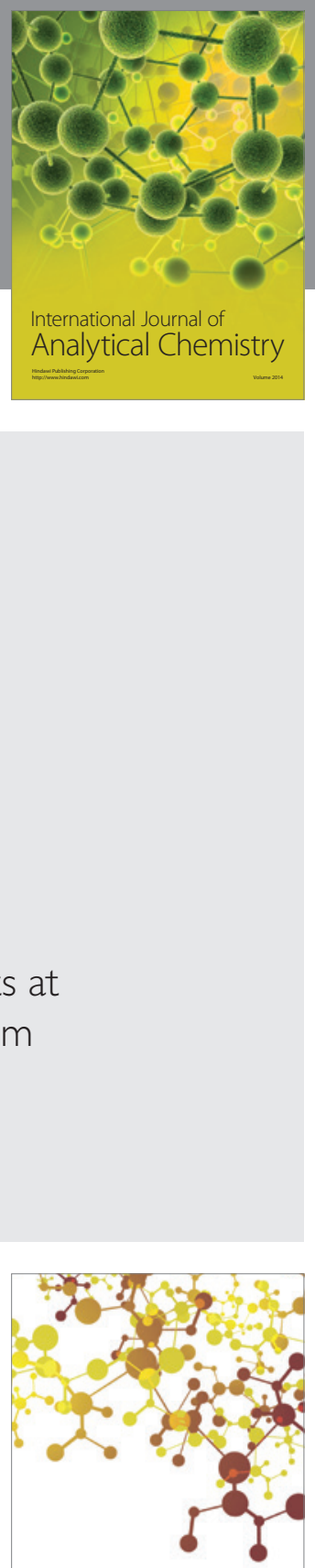

Journal of

Applied Chemistry
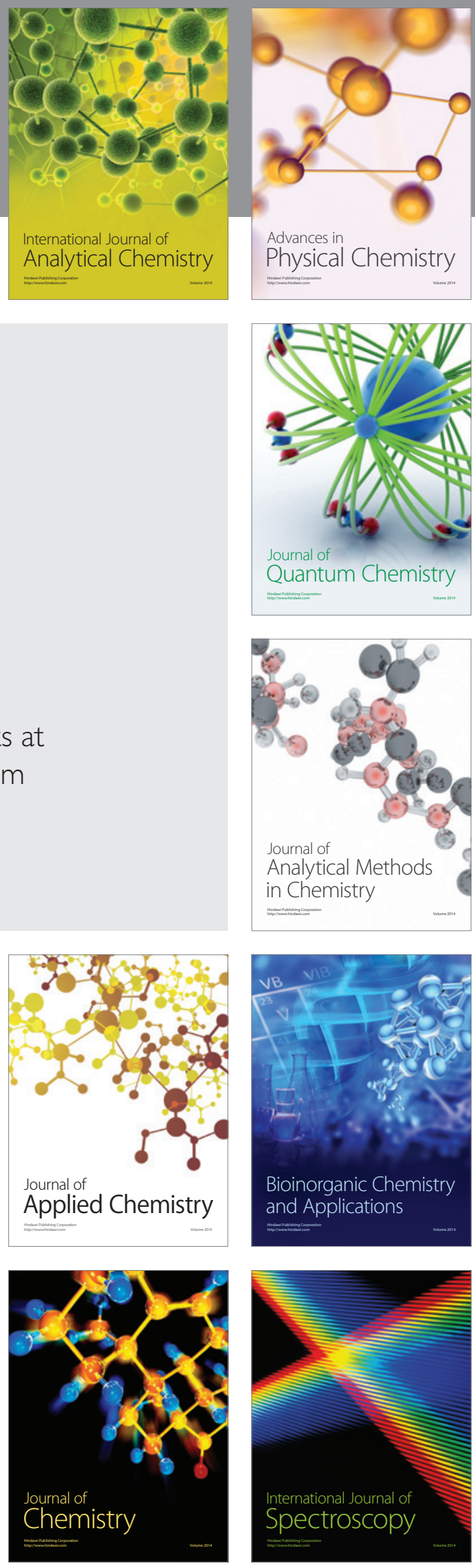